\title{
Development of a Reflective Ability Scale for Clinical Nurses
}

\author{
Akiko Nishimoto, ${ }^{*}$ Chika Tanimura, $\uparrow$ Reiko Okuda $\uparrow$ and Mika Fukada $\uparrow$ \\ *Tottori University Hospital, Yonago 683-8504, Japan and †School of Health Science, Faculty of Medicine, Tottori University, Yonago \\ 683-8503, Japan
}

\section{ABSTRACT}

Background Enhancement of reflective ability leads to improved nursing practice and individual growth. This study aimed to develop a reliable, validated scale that can effectively assess the reflective ability of clinical nurses.

Methods Study participants were 1,872 nurses. We developed an anonymous self-administered questionnaire consisting of 33 original scale items and used it to conduct a survey. The scale was developed based on a construct validity study using item analysis, exploratory factor analysis, and confirmatory factor analysis. Reliability was estimated with Cronbach's $\alpha$ values. Criterion-related validity was assessed using Pearson's correlation analysis.

Results There were 1,292 responses (response rate, 69.0\%). Responses from 1,262 subjects with no missing data were analyzed (valid response rate, 97.7\%). Based on the item analysis and exploratory factor analysis, we developed a trial scale model with 3 factors and 25 items. We named the first factor (Factor 1) "Recall Their Own Nursing Practice," the second factor (Factor 2) "Reflect on Their Own Nursing Practice" and the third factor (Factor 3) "Expand Their Own Nursing Practice". This model was modified based on modification indices from the confirmatory factor analysis. A model with 3 factors and 19 items was developed. It had acceptable fit indices (goodness of fit index $=0.914$; adjusted goodness of fit index $=0.890$; comparative fit index $=$ 0.949; root mean square error of approximation $=0.070$ ). Cronbach's $\alpha$ coefficients were 0.962 for all scale items, 0.922 for Factor 1, 0.918 for Factor 2, and 0.885 for Factor 3. The correlation coefficient between the model and the Professional Identity Scale of Nurses was 0.506 $(P<0.01)$.

\footnotetext{
Corresponding author: Akiko Nishimoto, RN

d20m6002a@edu.tottori-u.ac.jp

Received 2021 April 22

Accepted 2021 July 30

Online published 2021 August 24

Abbreviations: AGFI, adjusted goodness of fit index; CFA, confirmatory factor analysis; CFI, comparative fit index; EFA, exploratory factor analysis; GFI, goodness of fit index; G-P analysis, good-poor analysis; I-T correlation, item-total correlation; PISN, Professional Identity Scale of Nurses; RMSEA, root mean square error of approximation; SD, standard deviation
}

Conclusion We developed a reflective ability scale consisting of 3 factors and 19 items. We demonstrated its construct validity, reliability, and criterion-related validity. This scale can effectively assess the reflective ability of nurses.

Key words reflection; reflective ability; clinical nurses; scale development

Reflection is a practical process of looking back at experiences. ${ }^{1}$ The concept of reflection originated from the theory of "reflective thinking" by the educationalist and philosopher John Dewey. It is based on the idea of learning from experience. Donald Schön defined practitioners who act on their reflections as reflective practitioners. The reflective practitioner concept has drawn attention among nurses across the world. In Australia, reflective practice has been identified as a prerequisite competency for beginning nurse practitioners. In the United Kingdom and New Zealand, the development of reflective nurse practitioners has been advocated. ${ }^{2}$ According to Dewey, "reflection is the discernment of the relation between what we try to do and what happens in consequence." He also indicated that when some element of thought is added to experience, the quality of the experience changes, and the experience makes sense. ${ }^{3}$ According to Schön, reflection-in-action is "central to the art through which practitioners sometimes cope with the troublesome 'divergent situations of practice' and is 'the core of practice". 4

Nursing practice consists of individualized nursing actions performed in the context of the nurse-client relationship. How nursing knowledge and skills are applied to clients varies by nurse, client condition, and circumstance. Nurses develop their unique nursing practice through clinical experiences with nursing clients. ${ }^{5}$ Wisdom that is formed based on such nursing experiences is called practical wisdom. Reflection, which is a process of looking back and reviewing every single nursing action, is important to transforming experiences into practical wisdom.

In Japan, reflection has been regarded as an important learning strategy that leads to improved nursing practice as well as individual growth. ${ }^{1,}{ }^{6-9}$ However, there is no consensus on the definition of reflection in 
the context of nursing. For example, one study defines it as a process in which individuals make sense of their own acts through mental dialogue. ${ }^{1}$ Another study defines it as a process in which individuals look back at their nursing practice, find potential value and meaning in their nursing practice, and intentionally change their nursing practice to suit the circumstances. ${ }^{7}$ The common theme is that reflection is more than merely looking back at past events; instead, it entails nurses reviewing their own experiences, giving meaning to their actions, and bringing about a change in their perspective and way of thinking. ${ }^{1,7}$ Therefore, in this study, reflection is defined as a serious review of behavior undertaken by nurses as they gain unique experience by interacting with their clients, assigning meaning to their thoughts and actions, and synthesizing these elements as part of the process of thinking to generate practical wisdom.

Reflection is a cognitive skill, and although it can be acquired by training, it is difficult for this skill to become established in the present. ${ }^{7}$ For reflection to become established, it is important for nurses to use this skill to look back at past events, based on their requirements and circumstances, and strengthen their reflective abilities.

Nursing practice is a careful mixture of thoughts, emotions, and visible acts. ${ }^{10}$ To improve nursing practice, it is necessary for nurses to reflect on both the superficial process of looking back at the situation itself and the characteristics and tendencies in their way of thinking, as well as on their feelings and thoughts at that time. Considering that reflection is a thinking process that leads to high-quality nursing practice, it is inferred that the reflective ability of clinical nurses is comprised of the ability to look back intentionally on their own nursing practice, the ability to make sense of their own thoughts and actions, and the ability to gain practical wisdom from their experience in nursing practice.

A trigger for reflection is awareness of the inconsistencies between the expected and actual responses of clients to nursing practice. ${ }^{10}$ Thus, reflection is triggered by concerns raised from nursing practice. To engage in reflection that leads to the transformation of experiences into practical wisdom, it is important for nurses to find concerns raised from interactions with clients through careful observation of their own nursing practice. This way of reflective thinking cannot be acquired in a short period of time; however, it can be acquired by making such observation a habit in daily practice. To strengthen the ability to reflect and improve nursing practice, an assessment tool that can measure the current reflective ability of nurses is required.

In a previous study of reflective assessment, a reflection self-assessment scale for nursing students was developed. ${ }^{11}$ This self-assessment scale consists of three factors containing eight items whose reliability and validity have been demonstrated. It was demonstrated to be simple and easy to use. This scale was intended to be used for self-assessment of basic reflection skills by nursing students. Therefore, it does not include items to evaluate the ability to gain practical wisdom, which is a reflective ability. In another study, the first version of the Reflective Journal Assessment Index for Clinical Nurses was developed. ${ }^{6}$ This index consists of 30 items extracted from a reflective, qualitative and descriptive study conducted with clinical nurses. The reliability and validity of these items have been verified. This index can be used to assess reflection according to Gibbs' reflective cycle, which is a reflection learning framework consisting of description, feelings, evaluation, analysis, conclusion, and action plan. This index has been developed based on the assumption that a reflective journal can be used as a tool for descriptive reflective learning, and all items can be answered descriptively. Therefore, it may be effective for reflective skill training, but it is not suitable for the assessment of reflective ability. Other scales developed in previous studies include those that can assess nursing competence, ${ }^{12}, 13$ experiential learning, ${ }^{14}$ and oriented problem-solving behavior in nursing practice, ${ }^{15}$ which are common components of reflective ability. Some items contained in these scales may be able to assess some aspects of reflective ability, but these scales do not encompass the whole structure of reflective ability for which awareness of concerns is essential. In this context, there is a need for a scale that effectively assesses the reflective ability of clinical nurses. Therefore, this study aimed to develop a reliable, validated scale that can effectively assess the reflective ability of clinical nurses.

\section{SUBJECTS AND METHODS Study design}

This study was designed as a survey with the objective of developing a scale. The research design involved scale development. The scale was prepared in Japanese. Its development involved several steps, including item development, exploratory factor analysis (EFA), confirmatory factor analysis (CFA), reliability testing (internal consistency testing), and criterion-related validity testing.

\section{Definitions of terms}

In this study, reflective skill is defined as "a technique or strategy of reflection that can be acquired by learning."

Reflective ability refers to the ability to master the 
reflective skill, i.e., the ability to look back using reflective skill, based on necessity and circumstances. There is a need for nurses to look back to the past superficially, as well as to reflect with self-confrontation, which includes "the ability to look back intentionally on their own nursing practice", "the ability to make sense of their thoughts and actions" and "the ability to gain practical wisdom from their experience in nursing practice".

\section{Item development}

We believed that it would be difficult to detect any learning from internal experience perceived by the individual objectively at a superficial level, so we decided to develop a scale to measure reflective ability by performing a subjective evaluation of the nurses themselves. Question items were developed based on the first version of the Reflective Journal Assessment Index for Clinical Nurses. ${ }^{6}$ Other scales, including the Clinical Nursing Competence Self-Assessment Scale, ${ }^{12}$ Holistic Nursing Competence Scale, ${ }^{13}$ Experiential Learning Inventory, ${ }^{14}$ Self-Evaluation Scale of Oriented Problem Solving Behavior in Nursing Practice, ${ }^{15}$ and Nursing Excellence Scale in Clinical Practice, ${ }^{16}$ were used as references because they are reliable and validated scales and contain questions that can assess reflective ability, an essential part of nursing practice. At first, we developed a prototype scale consisting of 33 items and named it the Reflective Ability Scale. The item pool for the scale was developed under the supervision of two researchers who specialized in basic nursing science. The instructions were, "Please think back on a situation in which you were the nurse of a client (patient, family, etc.), and choose the response option that best describes your feelings about the actual circumstances". A six-point scale was used for response options (strongly agree, agree, somewhat agree, somewhat disagree, disagree, strongly disagree). A higher score indicated a higher reflective ability.

\section{Measurement tools}

The contents of the survey were not limited to reflective ability. The survey included 10 other items: age, sex, main job qualification, educational institution where the respondent obtained a nursing license, total years in nursing, clinical department, years of experience in the clinical department, image of the nurse that the respondent wants to be, opportunity for learning about reflection, and preference for nursing. The Professional Identity Scale of Nurses (PISN) ${ }^{17}$ was used as a reference. The reflection process begins with being aware of and looking back at concerns raised from nurse-client interactions. Factors of concern may include differences between the ideal and real self-images as a nurse. The PISN is a one-dimensional scale comprised of 20 items, including items for evaluating some elements of reflective ability, such as the ability to detect slight changes in patients and personal growth of nurses through nursing. Therefore, it was expected that nurses who have a high level of professional identity, which is a subjective selfimage as a nurse, also have a high level of reflective ability. The PISN uses a five-point scale for response options (true, somewhat true, neutral, somewhat untrue, untrue). Positive items were rated from five points (true of what I believe) to one point (untrue of what I believe). Negative items were rated from one point to five points.

\section{Subjects and data collection}

The survey was conducted from August to September 2019. Nurses working for advanced treatment hospitals, public medical facilities, or National Hospital Organization's medical facilities with $\geq 300$ beds were included. The reason we selected the above-mentioned hospitals is that they have good education systems, which provide numerous opportunities for training and education, which we believed would facilitate the appropriate understanding and evaluation of the meaning of the word reflection. The sample size required to meet the requirements for adequate statistical power was five to ten times the number of observation variables. Taking the response rate and missing values into account, we set the target sample size at 700 . Ultimately, 1,872 nurses from seven medical facilities were enrolled in the study.

\section{Study method}

An anonymous self-administered questionnaire was used. We mailed the request for survey participation and the questionnaire to the target medical facilities for distribution to study participants. Completed questionnaires were collected via a collection box at each facility and sent back to us by the investigator at each facility.

\section{Data analysis Item analysis}

As part of the item analysis, analyses of the frequency of missing values, pass rate, skewness, kurtosis, itemtotal correlation (I-T correlation), ceiling and floor effects, and inter-item correlation, as well as goodpoor analysis (G-P analysis), were performed. The acceptance criteria for the frequency of missing values and pass rate were defined as $4 \%$ and $80 \%$, respectively. A ceiling effect of $\geq 6$ and a floor effect of $\leq 1$ were considered to indicate response bias. For the I-T correlation, a correlation coefficient of $\leq 0.4$ was considered 
to denote a low correlation between an individual item and the overall score. ${ }^{18}$ For the inter-item correlation, a correlation coefficient of $\geq 0.7$ is often considered to demonstrate a positive inter-item correlation. ${ }^{19,20}$ In the present study, many items had an inter-item correlation coefficient of $\geq 0.7$, and they seemed to be necessary to evaluate reflective ability comprehensively. Therefore, we determined that there was similarity in the tendency of responses between items if the correlation coefficient was $\geq 0.75$.

\section{Construct validity}

EFA was performed to examine the construct validity using maximum likelihood estimation with promax rotation. The number of factors was determined based on eigenvalues $\geq 1$. Items with a factor loading of $\geq 0.4$ were selected. Items with high factor loading $(\geq 0.35)$ on factors other than belonging factors were considered to have low discrimination. For CFA, the goodness-offit of the factor model was estimated using covariance structure analysis. To determine the goodness-of-fit of the model, the goodness of fit index (GFI), comparative fit index (CFI), and root mean square error of approximation (RMSEA) were used as indices of statistical explainability, and the adjusted GFI (AGFI) was used as an index of stability. In general, models with a GFI of $\geq$ 0.9 , an AGFI of $\geq 0.9$, and a CFI of $\geq 0.95$ are considered acceptable. In addition, models with an RMSEA of $\leq$ 0.05 are considered to have a close fit, and those with an RMSEA of $\geq 0.1$ are considered to have a poor fit. ${ }^{21}$

\section{Criterion-related validity}

Criterion-related validity was determined by examining concurrent validity using Pearson's product moment correlation coefficients.

\section{Reliability}

Reliability was determined by calculating Cronbach's $\alpha$ coefficients, which indicate internal consistency. Generally, a Cronbach's $\alpha$ coefficient of $\geq 0.7$ demonstrates internal consistency. ${ }^{18}$

\section{Ethical considerations}

This study was approved by the Tottori University Faculty of Medicine Ethics Committee (approval number 19A029). Study participants were provided with a form informing them of the purpose and methods of the study and that participation in the study was voluntary. Study participants were also informed that they would not incur any disadvantage by participating or not participating in the study and that their personal information would be protected. Study participants were considered to have consented to participate in the study upon returning the questionnaire. They were informed that consent could not be withdrawn after the questionnaire was returned because collected questionnaires would be anonymized.

\section{RESULTS Characteristics of the study participants}

Among 1,872 nurses to whom the questionnaire was sent, 1,292 responded (response rate, 69.0\%). Of these responses, data from 1,262 participants without missing values in the prototype Reflective Ability Scale were included in the analyses (valid response rate, 97.7\%).

Study participants consisted of 127 males and 1,134 females, with a mean age of $37.17 \pm 10.87$ years (range, 20-65 years). Their main job description was nurse ( $n$ $=1,196,94.8 \%)$, associate nurse $(n=6,0.5 \%)$, public health nurse $(n=3,0.2 \%)$, or midwife $(n=55,4.4 \%)$. Regarding having the opportunity for learning about reflection, 670 subjects (53.1\%) answered "yes", and 555 $(44.0 \%)$ answered "no". Table 1 summarizes the characteristics of the study participants.

\section{Item analysis}

Means and standard deviations (SD) of scores on each of the 33 items in the prototype Reflective Ability Scale were calculated. Item analysis showed that no items met the criteria for frequency of missing values ( $\geq 4 \%$ ), pass rate $(80 \%)$, ceiling effect or floor effect. Both skewness and kurtosis were less than \pm 2.0 . In the I-T correlation analysis, one item (R1) had a correlation coefficient of $<0.4$. In the inter-item correlation analysis, four items (two pairs: R18-R21 and R32-R33) had a correlation coefficient of $>0.75$. In the G-P analysis, there were significant differences in the scores of all individual items between the group with a higher total score and the group with a lower total score $\left({ }^{* *} P<0.01\right)$. Content validity was evaluated based on these analyses. One item (R1) with a low I-T correlation was excluded from the analysis. Furthermore, of four items (two pairs: R18-R21 and R32-R33) with a high inter-item correlation, two items (one item from each pair: R18 and R33) that were determined to be evaluable with other item were also excluded from the analysis. Table 2 shows the summary of the item analysis results.

\section{Exploratory factor analysis}

EFA was performed for the remaining 30 items. Defining the number of factors by the number of eigenvalues $\geq 1$, we examined the scree plot to understand the factor structure of the scale. A three-factor structure seemed valid. Thus, we repeated the factor analysis 
Table 1. Characteristics of the study participants $(n=1,262)$

\begin{tabular}{|c|c|c|}
\hline Variable & Number $(\%)$ & Mean \pm SD (range) \\
\hline Age (range), years & & $37.17 \pm 10.87(20-65)$ \\
\hline \multicolumn{3}{|l|}{ Sex } \\
\hline Male & $127(10.1)$ & \\
\hline Female & $1,134(89.9)$ & \\
\hline \multicolumn{3}{|l|}{ Main job description } \\
\hline Nurse & $1,196(94.8)$ & \\
\hline Associate Nurse & $6(0.5)$ & \\
\hline Public Health Nurse & $3(0.2)$ & \\
\hline Midwife & $55(4.4)$ & \\
\hline \multicolumn{3}{|c|}{ Educational institution where nursing license was obtained } \\
\hline Four-year college & $254(20.1)$ & \\
\hline Three-year college & $139(11.0)$ & \\
\hline Training school for nurses & $869(68.9)$ & \\
\hline Total years in nursing & & $14.25 \pm 10.38(1-43)$ \\
\hline \multicolumn{3}{|l|}{ Clinical department } \\
\hline General hospital ward & $779(61.7)$ & \\
\hline Outpatient clinic & $89(7.1)$ & \\
\hline Operating room & $80(6.3)$ & \\
\hline Intensive care unit & $158(12.5)$ & \\
\hline Other & $139(11.0)$ & \\
\hline \multicolumn{3}{|c|}{ Image of nurse the respondent wants to be } \\
\hline I have a clear image & $197(15.6)$ & \\
\hline I have a vague image & $921(73.0)$ & \\
\hline I don't have any image & $140(0.3)$ & \\
\hline \multicolumn{3}{|c|}{ Opportunity for learning about reflection } \\
\hline I had & $670(53.1)$ & \\
\hline I never had & $555(44.0)$ & \\
\hline
\end{tabular}

using maximum likelihood estimation with promax rotation. Defining the number of factors by the number of eigenvalues $\geq 1$, items with a factor loading of $<0.4$, and items with high factor loading on factors other than belonging factors that were considered to have low discrimination were excluded. Three researchers cooperatively examined the content validity of the scale items and created a trial model consisting of 3 factors and 25 items. Cumulative contribution rate of the three factors was $63.4 \%$. Table 3 shows the factor patterns and inter-factor correlations after repeated maximum likelihood estimation with promax rotation.

Ten items had high loading on the first factor (Factor 1), i.e. the factor that assesses individuals on the ability to recall their own experiences and their clients' experiences in nursing situations. Therefore, we named Factor
1 "Recall Their Own Nursing Practice." The second factor (Factor 2) comprised 8 items and is directed towards their thoughts and actions in concerning situations (selfconfrontation), and items that were reflected on, such as evaluation by looking back, showed high factor loading. Therefore, we named Factor 2 "Reflect on Their Own Nursing Practice." The third factor (Factor 3) comprised 7 items, and the items that involved looking back on their feelings in concerning situations, recapturing and making sense from a new perspective, and finding future-oriented nursing methods were observed to have high factor loading. Therefore, we named Factor 3 "Expand Their Own Nursing Practice".

\section{Confirmatory factor analysis}

CFA was performed for the model consisting of 3 
Table 2. Results of the item analysis

\begin{tabular}{|c|c|c|c|c|c|c|c|c|}
\hline $\begin{array}{l}\text { Item } \\
\text { number }\end{array}$ & & Mean & SD & Skewness & Kurtosis & $\begin{array}{l}\text { I-T cor- } \\
\text { relation }\end{array}$ & $\begin{array}{l}\text { Mean }+ \\
\text { SD }\end{array}$ & $\begin{array}{l}\text { Mean- } \\
\text { SD }\end{array}$ \\
\hline $\mathrm{R} 1$ & $\begin{array}{l}\text { I have concerning situations in my daily } \\
\text { nursing practice. }\end{array}$ & 4.14 & 0.831 & -0.346 & 0.418 & $0.341^{* *}$ & 4.973 & 3.312 \\
\hline $\mathrm{R} 2$ & $\begin{array}{l}\text { I can explain what knowledge I used for } \\
\text { judging the circumstances of clients in con- } \\
\text { cerning situations. }\end{array}$ & 3.92 & 0.704 & -0.219 & 0.584 & $0.624 * *$ & 4.627 & 3.219 \\
\hline $\mathrm{R} 3$ & $\begin{array}{l}\text { I reframe my experiences in concerning } \\
\text { situations using various perspectives. }\end{array}$ & 3.89 & 0.710 & -0.231 & 0.299 & $0.705^{* *}$ & 4.604 & 3.184 \\
\hline $\mathrm{R} 4$ & $\begin{array}{l}\text { I become aware of certain aspects of nurs- } \\
\text { ing that I had been previously unaware of } \\
\text { through my experiences in concerning situ- } \\
\text { ations. }\end{array}$ & 4.14 & 0.677 & -0.172 & 1.354 & $0.711 * *$ & 4.812 & 3.459 \\
\hline $\mathrm{R} 5$ & $\begin{array}{l}\text { I can explain why I felt the way I did during } \\
\text { concerning situations. }\end{array}$ & 4.01 & 0.742 & -0.182 & 0.402 & $0.730 * *$ & 4.754 & 3.270 \\
\hline R6 & $\begin{array}{l}\text { I can explain how I predicted the effects of } \\
\text { my actions on clients in concerning situa- } \\
\text { tions. }\end{array}$ & 3.99 & 0.712 & -0.175 & 0.756 & $0.774 * *$ & 4.705 & 3.281 \\
\hline R7 & $\begin{array}{l}\text { I make sense of my experiences in concern- } \\
\text { ing situations. }\end{array}$ & 3.92 & 0.763 & -0.320 & 0.642 & $0.786^{* *}$ & 4.680 & 3.154 \\
\hline $\mathrm{R} 8$ & $\begin{array}{l}\text { I find my own way of nursing through expe- } \\
\text { riences in concerning situations. }\end{array}$ & 4.12 & 0.700 & -0.172 & 0.960 & $0.784^{* *}$ & 4.822 & 3.422 \\
\hline R9 & $\begin{array}{l}\text { I can recall my behaviors in concerning } \\
\text { situations. }\end{array}$ & 3.99 & 0.739 & -0.236 & 0.848 & $0.776^{* *}$ & 4.731 & 3.253 \\
\hline $\mathrm{R} 10$ & $\begin{array}{l}\text { I can recall the expressions of clients in con- } \\
\text { cerning situations. }\end{array}$ & 4.16 & 0.712 & -0.314 & 1.433 & $0.758 * *$ & 4.867 & 3.443 \\
\hline R11 & $\begin{array}{l}\text { I reflect on how the characteristics of my } \\
\text { way of thinking in concerning situations af- } \\
\text { fected my nursing actions. }\end{array}$ & 3.80 & 0.761 & -0.299 & 0.456 & $0.776^{* *}$ & 4.563 & 3.041 \\
\hline R12 & $\begin{array}{l}\text { Experiences in concerning situations have } \\
\text { affected me as a nurse. }\end{array}$ & 4.27 & 0.765 & -0.097 & 0.966 & $0.679 * *$ & 5.036 & 3.505 \\
\hline $\mathrm{R} 13$ & $\begin{array}{l}\text { I can recall behaviors of clients that resulted } \\
\text { from my actions in concerning situations. }\end{array}$ & 3.99 & 0.722 & -0.312 & 1.085 & $0.797 * *$ & 4.710 & 3.266 \\
\hline R14 & $\begin{array}{l}\text { I can explain my judgment about support } \\
\text { necessary for clients in concerning situa- } \\
\text { tions. }\end{array}$ & 4.08 & 0.701 & -0.204 & 0.783 & $0.813^{* *}$ & 4.778 & 3.376 \\
\hline $\mathrm{R} 15$ & $\begin{array}{l}\text { I look back on my experiences through talk- } \\
\text { ing with someone about concerning situa- } \\
\text { tions I faced. }\end{array}$ & 4.17 & 0.817 & -0.514 & 0.977 & $0.704^{* *}$ & 4.983 & 3.348 \\
\hline R16 & $\begin{array}{l}\text { I find laws that are common in various nurs- } \\
\text { ing settings through experiences in concern- } \\
\text { ing situations. }\end{array}$ & 3.72 & 0.833 & -0.281 & 0.281 & $0.734 * *$ & 4.557 & 2.892 \\
\hline R17 & $\begin{array}{l}\text { I can recall behaviors of clients in concern- } \\
\text { ing situations. }\end{array}$ & 4.17 & 0.694 & -0.207 & 1.607 & $0.775^{* *}$ & 4.860 & 3.473 \\
\hline R18 & $\begin{array}{l}\text { I can explain the intentions of my behaviors } \\
\text { in concerning situations. }\end{array}$ & 4.04 & 0.711 & -0.181 & 0.916 & $0.821^{* *}$ & 4.754 & 3.332 \\
\hline R19 & $\begin{array}{l}\text { I reflect on how my actions affected clients } \\
\text { in concerning situations. }\end{array}$ & 3.87 & 0.743 & -0.143 & 0.478 & $0.814 * *$ & 4.618 & 3.132 \\
\hline R20 & $\begin{array}{l}\text { I find ways of nursing that may be applicable } \\
\text { to other situations through experiences in } \\
\text { concerning situations. }\end{array}$ & 3.99 & 0.697 & -0.274 & 0.589 & $0.787^{* *}$ & 4.692 & 3.297 \\
\hline $\mathrm{R} 21$ & $\begin{array}{l}\text { I can explain how I judged clients' circum- } \\
\text { stances in concerning situations. }\end{array}$ & 4.03 & 0.687 & -0.233 & 0.741 & $0.840 * *$ & 4.720 & 3.345 \\
\hline
\end{tabular}


Table 2. Results of the item analysis (Continued)

\begin{tabular}{|c|c|c|c|c|c|c|c|c|}
\hline $\begin{array}{l}\text { Item } \\
\text { number }\end{array}$ & & Mean & SD & Skewness & Kurtosis & $\begin{array}{l}\text { I-T cor- } \\
\text { relation }\end{array}$ & $\begin{array}{l}\text { Mean }+ \\
\text { SD }\end{array}$ & $\begin{array}{l}\text { Mean- } \\
\text { SD }\end{array}$ \\
\hline R22 & $\begin{array}{l}\text { I can recall how I felt during concerning } \\
\text { situations. }\end{array}$ & 4.09 & 0.704 & -0.240 & 1.098 & $0.793 * *$ & 4.796 & 3.388 \\
\hline $\mathrm{R} 23$ & $\begin{array}{l}\text { I reflect on my actions in concerning situa- } \\
\text { tions in light of the principles of nursing. }\end{array}$ & 3.74 & 0.771 & -0.245 & 0.225 & $0.763^{* *}$ & 4.512 & 2.970 \\
\hline R24 & $\begin{array}{l}\text { I can recall my past experiences that I used } \\
\text { for judging clients' circumstances in con- } \\
\text { cerning situations. }\end{array}$ & 3.99 & 0.727 & -0.366 & 1.227 & $0.811^{* *}$ & 4.715 & 3.261 \\
\hline $\mathrm{R} 25$ & $\begin{array}{l}\text { I can recall circumstances surrounding con- } \\
\text { cerning situations. }\end{array}$ & 4.05 & 0.696 & -0.311 & 1.220 & $0.777 * *$ & 4.748 & 3.356 \\
\hline R26 & $\begin{array}{l}\text { I look back and evaluate my thought pro- } \\
\text { cesses in concerning situations. }\end{array}$ & 3.88 & 0.778 & -0.410 & 0.731 & $0.785^{* *}$ & 4.656 & 3.099 \\
\hline R27 & $\begin{array}{l}\text { I can recall the content of conversations with } \\
\text { clients during concerning situations. }\end{array}$ & 4.09 & 0.692 & -0.433 & 1.742 & $0.796^{* *}$ & 4.779 & 3.395 \\
\hline $\mathrm{R} 28$ & $\begin{array}{l}\text { I evaluate the validity of the knowledge that } \\
\text { I used for making judgments in concerning } \\
\text { situations. }\end{array}$ & 3.79 & 0.760 & -0.304 & 0.766 & $0.762 * *$ & 4.546 & 3.026 \\
\hline R29 & $\begin{array}{l}\text { I am aware of the characteristics and tenden- } \\
\text { cies of my way of thinking in concerning } \\
\text { situations. }\end{array}$ & 4.00 & 0.716 & -0.338 & 0.922 & $0.788^{* *}$ & 4.716 & 3.284 \\
\hline R30 & $\begin{array}{l}\text { I can explain the reasons for my behaviors } \\
\text { in concerning situations. }\end{array}$ & 4.05 & 0.705 & -0.275 & 1.202 & $0.821^{* *}$ & 4.756 & 3.346 \\
\hline R31 & $\begin{array}{l}\text { I think of reasons why I was concerned } \\
\text { about certain situations. }\end{array}$ & 4.10 & 0.726 & -0.414 & 1.500 & $0.772 * *$ & 4.824 & 3.373 \\
\hline R32 & $\begin{array}{l}\text { I reflect on how my emotions and attitudes } \\
\text { affected clients in concerning situations. }\end{array}$ & 3.91 & 0.750 & -0.327 & 0.734 & $0.816^{* *}$ & 4.662 & 3.161 \\
\hline R33 & $\begin{array}{l}\text { I have become aware of certain aspects of } \\
\text { myself that I had been previously unaware } \\
\text { of through my experiences in concerning } \\
\text { situations. }\end{array}$ & 4.08 & 0.721 & -0.444 & 1.540 & $0.819 * *$ & 4.796 & 3.354 \\
\hline
\end{tabular}

$* * P<0.01$. I-T correlation, item-total correlation; SD, standard deviation.

factors and 25 items. The analysis showed that the fit indices of the model did not reach an acceptable level $(\mathrm{GFI}=0.857, \mathrm{AGFI}=0.831, \mathrm{CFI}=0.919, \mathrm{RMSEA}=$ 0.077). Therefore, we modified the model based on the modification indices. Three researchers examined the content validity of the items and developed a model consisting of 3 factors and 19 items (Fig. 1). The fit indices between the model and data were acceptable (GFI $=0.914, \mathrm{AGFI}=0.890, \mathrm{CFI}=0.949, \mathrm{RMSEA}=0.070$ ). The corresponding standardized coefficients were statistically significant $(* * * P<0.001)$. Table 4 shows the factors and items of the Reflective Ability Scale.

Pearson's correlation coefficient between the three factors was as follows: $0.833(* * * P<0.001)$ between the first and second factors and $0.787(* * * P<0.001)$ between the first and third factors. A high correlation of $0.795(* * * P<0.001)$ was confirmed between the second and third factors.

\section{Criterion-related validity}

Pearson's correlation coefficient between scores on our Reflective Ability Scale and the PISN, which was used as the reference criteria, was $0.506(* * * P<0.001)$, indicating a moderate positive correlation.

\section{Reliability}

Cronbach's $\alpha$ coefficients for internal consistency were $0.962,0.922,0.918$, and 0.885 for all items of the Reflective Ability Scale, "Recall Their Own Nursing Practice" (Factor 1), "Reflect on Their Own Nursing Practice" (Factor 2), and "Expand Their Own Nursing Practice" (Factor 3), respectively.

\section{DISCUSSION}

Previous studies did not reach a consensus on the concept of reflective ability. In this study, therefore, we defined the reflective ability of clinical nurses as 1) the 
Table 3. Exploratory factor analysis of the prototype Reflective Ability Scale $(n=1,262)$

\begin{tabular}{|c|c|c|c|c|c|}
\hline \multirow{2}{*}{ No. } & \multirow{2}{*}{ Items } & \multicolumn{3}{|c|}{ Factor loading } & \multirow{2}{*}{ Commonality } \\
\hline & & Factor 1 & Factor 2 & Factor 3 & \\
\hline \multicolumn{6}{|c|}{ Recall Their Own Nursing Practice } \\
\hline R17 & I can recall behaviors of clients in concerning situations. & 0.870 & -0.004 & -0.057 & 0.679 \\
\hline $\mathrm{R} 22$ & I can recall how I felt during concerning situations. & 0.826 & -0.043 & 0.054 & 0.695 \\
\hline R27 & I can recall the content of conversations with clients in concerning situations. & 0.741 & 0.220 & -0.121 & 0.692 \\
\hline R10 & I can recall the expressions of clients in concerning situations. & 0.731 & -0.114 & 0.185 & 0.624 \\
\hline $\mathrm{R} 31$ & I think of reasons why I was concerned about certain situations. & 0.679 & 0.211 & -0.080 & 0.630 \\
\hline R12 & Experiences in concerning situations have affected me as a nurse. & 0.673 & -0.124 & 0.149 & 0.485 \\
\hline R30 & I can explain the reasons for my behaviors in concerning situations. & 0.655 & 0.177 & 0.045 & 0.702 \\
\hline $\mathrm{R} 21$ & I can explain how I judged clients' circumstances in concerning situations. & 0.521 & 0.173 & 0.209 & 0.708 \\
\hline R13 & $\begin{array}{l}\text { I can recall behaviors of clients that resulted from my actions in concerning } \\
\text { situations. }\end{array}$ & 0.507 & 0.156 & 0.184 & 0.626 \\
\hline R15 & $\begin{array}{l}\text { I look back on my experiences through talking with someone about concern- } \\
\text { ing situations I faced. }\end{array}$ & 0.469 & 0.134 & 0.134 & 0.477 \\
\hline \multicolumn{6}{|c|}{ Reflect on Their Own Nursing Practice } \\
\hline $\mathrm{R} 23$ & $\begin{array}{l}\text { I reflect on my actions in concerning situations in light of the principles of } \\
\text { nursing. }\end{array}$ & -0.142 & 0.897 & 0.086 & 0.730 \\
\hline $\mathrm{R} 28$ & $\begin{array}{l}\text { I evaluate the validity of the knowledge that I used for making judgments in } \\
\text { concerning situations. }\end{array}$ & -0.022 & 0.890 & -0.037 & 0.715 \\
\hline $\mathrm{R} 26$ & I look back and evaluate my thought processes in concerning situations. & 0.191 & 0.748 & -0.099 & 0.690 \\
\hline R19 & I reflect on how my actions affected clients in concerning situations. & 0.221 & 0.543 & 0.111 & 0.673 \\
\hline R16 & $\begin{array}{l}\text { I find laws that are common in various nursing settings through experiences } \\
\text { in concerning situations. }\end{array}$ & 0.024 & 0.516 & 0.251 & 0.554 \\
\hline R29 & $\begin{array}{l}\text { I am aware of the characteristics and tendencies of my way of thinking in } \\
\text { concerning situations. }\end{array}$ & 0.332 & 0.514 & -0.004 & 0.638 \\
\hline R11 & $\begin{array}{l}\text { I reflect on how the characteristics of my way of thinking in concerning situa- } \\
\text { tions affected my nursing actions. }\end{array}$ & 0.068 & 0.513 & 0.261 & 0.620 \\
\hline R24 & $\begin{array}{l}\text { I can recall my past experiences that I used for judging clients' circumstances } \\
\text { in concerning situations. }\end{array}$ & 0.304 & 0.466 & 0.104 & 0.665 \\
\hline \multicolumn{6}{|c|}{ Expand Their Own Nursing Practice } \\
\hline R5 & I can explain why I felt the way I did during concerning situations. & 0.158 & -0.126 & 0.780 & 0.658 \\
\hline R6 & $\begin{array}{l}\text { I can explain how I predicted the effects of my actions on clients in concern- } \\
\text { ing situations. }\end{array}$ & 0.048 & 0.038 & 0.778 & 0.713 \\
\hline $\mathrm{R} 2$ & $\begin{array}{l}\text { I can explain what knowledge I used for judging the circumstances of clients } \\
\text { in concerning situations. }\end{array}$ & -0.035 & 0.012 & 0.705 & 0.473 \\
\hline R3 & I reframe my experiences in concerning situations using various perspectives. & -0.124 & 0.198 & 0.704 & 0.589 \\
\hline R4 & $\begin{array}{l}\text { I become aware of certain aspects of nursing that I had been previously un- } \\
\text { aware of through my experiences in concerning situations. }\end{array}$ & 0.164 & 0.030 & 0.577 & 0.540 \\
\hline R8 & I find my own way of nursing through experiences in concerning situations. & 0.276 & 0.041 & 0.530 & 0.632 \\
\hline \multirow[t]{5}{*}{ R7 } & I make sense of my experiences in concerning situations. & 0.040 & 0.317 & 0.506 & 0.651 \\
\hline & Cumulative contribution rate $(\%)$ & 57.363 & 60.400 & 63.442 & \\
\hline & Inter-factor correlation Factor 1 & - & 0.787 & 0.764 & \\
\hline & Factor 2 & & - & 0.754 & \\
\hline & Factor 3 & & & - & \\
\hline
\end{tabular}

Exploratory factor analysis was performed using maximum likelihood estimation with promax rotation. 


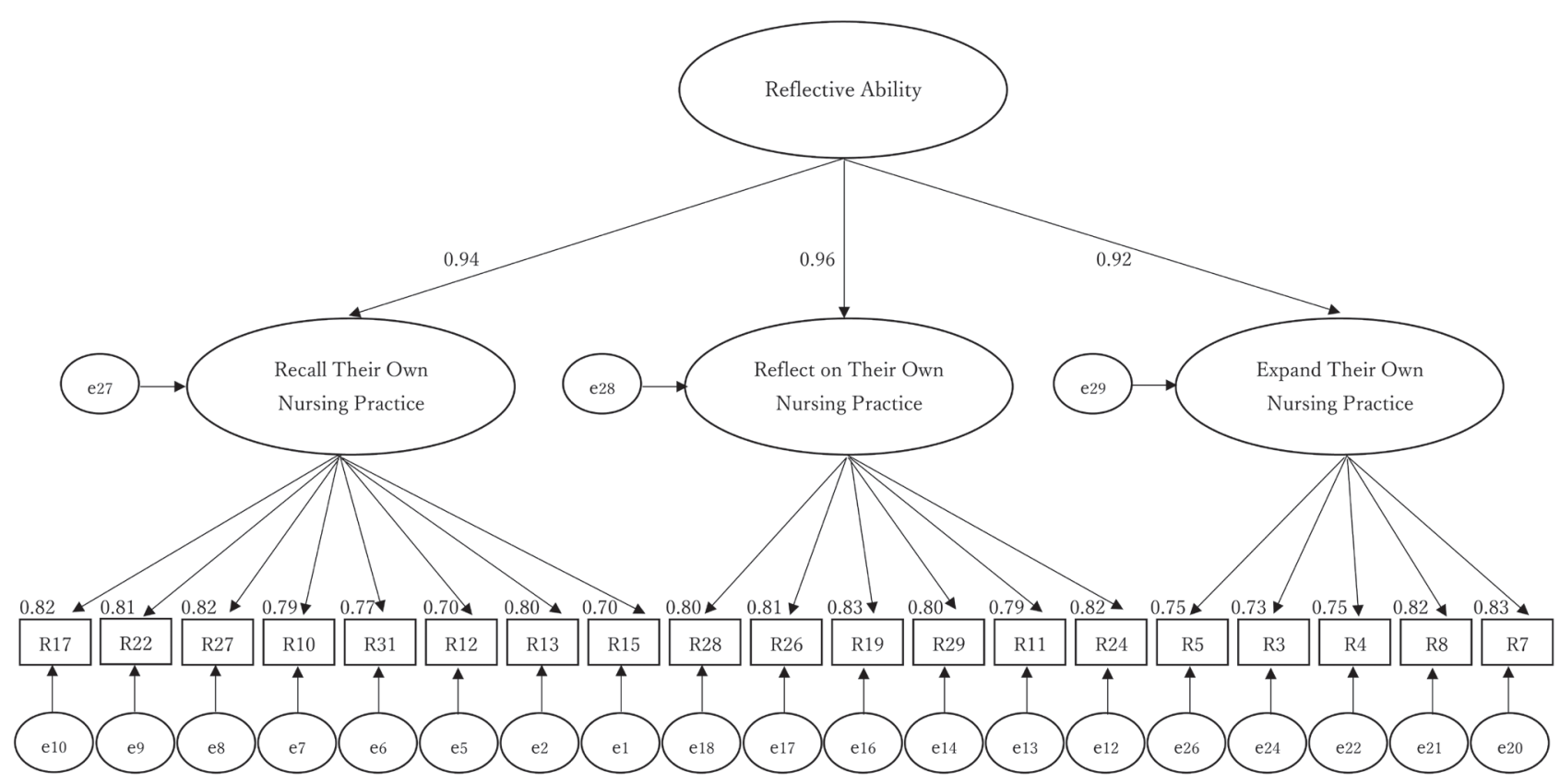

$\mathrm{GFI}=0.914, \mathrm{AGFI}=0.890, \mathrm{CFI}=0.949, \mathrm{RMSEA}=0.070$

Fig. 1. Final model of the Reflective Ability Scale structure after confirmatory factor analysis. Standardized coefficients (path coefficients) are presented. All standardized coefficients were statistically significant $(* * * P<0.001)$. AGFI, adjusted GFI; CFI, comparative fit index; e, error variable; GFI, goodness of fit index; RMSEA, root mean square error of approximation; R\#\#, item number.

ability to look back intentionally on their own nursing practice, 2) the ability to make sense of their own thoughts and actions and 3) the ability to gain practical wisdom from their experience in nursing practice. The goal of this study was to develop a reliable, validated scale that can effectively assess the reflective ability of clinical nurses. EFA results suggested that a reflective ability scale should have three factors ("Recall Their Own Nursing Practice", "Reflect on Their Own Nursing Practice" and "Expand Their Own Nursing Practice") with 25 items. However, the cumulative contribution rate of the three factors is $63.4 \%$, which is not a high value, and it cannot be denied that there are factors other than the extracted factors that are affecting the variation of the observed variables. Fit indices in the CFA indicated that the modified model consisting of 3 factors with 19 items had a close fit. Therefore, the structure of the modified model (finalized version) was considered valid. In this study, it was shown that the relationship between the reflective ability and each of the individual factors, and the relationship between the factors and each item have statistical explanatory power. A secondorder factor model was constructed with "reflective ability" as the epistatic factor, and "Recall Their Own Nursing Practice" (Factor 1), "Reflect on Their Own Nursing Practice" (Factor 2), and "Expand Their Own Nursing Practice" (Factor 3) as the hypostatic factors.
Factor 1, "Recall Their Own Nursing Practice" involved nurses remembering their own feelings and behavior and the client's speech and facial expressions in a concerning situation, and consisted of the details of nursing practice that were intentionally remembered, such as "I think of reasons why I was concerned about certain situations" and "I look back on my experiences through talking with someone about the concerning situations I faced". We believed that this resembled the item "the ability to look back intentionally on their own nursing practice" that formed part of the concept of reflective ability. Factor 2, "Reflect on Their Own Nursing Practice", involved self-confrontation and reflection, such as "I look back and evaluate my thought processes in concerning situations", "I reflect on how my actions affected clients in concerning situations", and "I am aware of the characteristics and tendencies of my way of thinking in concerning situations". We believed that this was similar to "the ability to make sense of their own thoughts and actions", which formed part of the concept of reflective ability. Factor 3, "Expand Their Own Nursing Practice", is made up of details of the acquisition of new awareness, based on internal experiences due to making sense of the behavior, such as "I reframe my experiences in concerning situations using various perspectives", "I find my own way of nursing through experiences in concerning situations". We believed that 
Table 4. Items in the finalized Reflective Ability Scale

\begin{tabular}{ll}
\hline Factor 1: Recall Their Own Nursing Practice \\
R17 & I can recall behaviors of clients in concerning situations. \\
R22 & I can recall how I felt during concerning situations. \\
R27 & I can recall the content of conversations with clients in concerning situations. \\
R10 & I can recall the expressions of clients in concerning situations. \\
R31 & I think of reasons why I was concerned about certain situations. \\
\hline R12 & Experiences in concerning situations have affected me as a nurse. \\
\hline R13 & I can recall behaviors of clients that resulted from my actions in concerning situations. \\
\hline R15 & I look back on my experiences through talking with someone about concerning situations I faced. \\
\hline Factor 2: Reflect on Their Own Nursing Practice \\
\hline R28 & I evaluate the validity of the knowledge that I used for making judgments in concerning situations. \\
\hline R26 & I look back and evaluate my thought processes in concerning situations. \\
\hline R19 & I reflect on how my actions affected clients in concerning situations. \\
\hline R29 & I am aware of the characteristics and tendencies of my way of thinking in concerning situations. \\
\hline R11 & I reflect on how the characteristics of my way of thinking in concerning situations affected my nursing actions. \\
\hline R24 & I can recall my past experiences that I used for judging clients' circumstances in concerning situations. \\
\hline Factor 3: Expand Their Own Nursing Practice \\
\hline R5 & I can explain why I felt the way I did during concerning situations. \\
\hline R3 & I reframe my experiences in concerning situations using various perspectives. \\
\hline R4 & I have become aware of certain aspects of nursing that I had been previously unaware of through my experiences in \\
R8 & concerning situations. \\
\hline R7 & I find my own way of nursing through experiences in concerning situations. \\
\hline
\end{tabular}

this was similar to "the ability to gain practical wisdom from experience in nursing practice", which formed part of the concept of reflective ability. Therefore, it can be said that the three factors on the reflective ability scale extracted in this study reflect a structure that shows the concept of reflective ability.

The correlation coefficient between these three factors on the Reflective Ability Scale was high, suggesting that the three factors are closely associated with each other. Reflection involves not simply a sequence of ideas, but a consequence - a consecutive ordering in such a way that each determines the next as its proper outcome, while each in turn depends upon its predecessors. ${ }^{22}$ Considering these characteristics of reflection, we believe that the three factors that make up the reflective ability scale are continuous thoughts that cannot be separated. It is important to recall concerning nursing practice situations to reflect on nursing practice, and it is important to reflect on the experiences in concerning situations to expand nursing practice. In other words, each reflective ability determines the next step as a consequence, and together, they are believed to make up a factor structure in which the subsequent steps are dependent upon the preceding steps (it can be reflected on because it can be recalled, and what is reflected on becomes an internal experience and can be expanded).

The reflective cycle advocated by Gibbs is an application of Kolb's empirical learning model of "learning and growing through experience," which presupposes Dewey's learning theory of "continuity of experience." It is used for learning reflection in nursing. The reflective cycle is made up of the following stages: stage 1 (description) "what happened", stage 2 (feeling) "what I felt", stage 3 (evaluation) "what was good and what was not good about this experience", stage 4 (analysis) "what does this situation mean", stage 5 (conclusion) "what else did you do", and stage 6 (action plan) "what to do if it happens again". The factor structure extracted in this study recalls the words and expressions of clients and the feelings of nurses in concerning situations during nursing practice, in addition to reflecting on the connection between the nurses' own thoughts and actions at that time. By incorporating this as an internal experience, it may serve to this expand the wisdom found 
in connection with future experiences during nursing practice, and provides an ordered factor structure; thus, we believe that it resembles the reflective cycle.

Nursing practice is supported by internalized feelings, the characteristics of the individual nurse's way thinking, and the experiences of individual nurses. Nursing practice is based on their unspoken judgment. Reflection is important for individuals to have insight into their self-image as a nurse and to be aware of their internalized feelings, the characteristics of "my way" thinking, and experiences while intentionally looking back at their at nursing practice and making sense of their thoughts and actions. Fred A. J. Korthagen developed the ALACT model to describe the ideal process of learning, consisting of five phases: 1) Action, 2) Looking back on action, 3) Awareness of essential aspects, 4) Creating alternative methods of action and 5) Trial. This model indicates the necessity of focusing on the internal entities that unconsciously guide human behavior, such as feelings, values, and behavioral tendencies that have created the situation, rather than to focus only on superficial behavior. According to this model, the core of reflection on a situation lies in Phase 3 , which is characterized by awareness of the essential aspects. Phase 3 is an important step in the process of schematization (process to make sense of and conceptualize experiences). ${ }^{23}$ Therefore, sufficient reflection cannot be reached only by reviewing what an individual was thinking or feeling during a certain situation and considering whether it was good or bad. ${ }^{24}$ Instead, it is important for individuals to reflect on their internalized feelings, characteristics of "my way" thinking, and experiences, and to expand their thoughts. The reflective ability scale, which consists of Factor 1 "Recall Their Own Nursing Practice", Factor 2 "Reflect on Their Own Nursing Practice", and Factor 3 "Expand Their Own Nursing Practice", can be referred to as a scale that recalls the characteristics of potential feelings and ways of thinking of the person concerned, as well as previous experiences, and provides the details necessary for reflective ability, including items to analyze whether reflection is actually occurring.

In the analysis of criterion-related validity, there was a moderate positive correlation between the scores of our Reflective Ability Scale and the PISN, which was used for reference. The PISN includes items for evaluating some elements of reflective ability, such as the ability to detect slight changes in patients and personal growth of nurses through nursing. The analysis showed a correlation between the professional identity of nurses measured with the PISN and reflective ability measured with our scale, suggesting that our scale had criterion-related validity. The correlation between the professional identity of nurses measured by the PISN and the reflective ability measured by our scale demonstrated the criterion-related validity of our scale. In the reliability study, Cronbach's $\alpha$ coefficients for all items and Factors 1, 2 and 3 of our scale indicated that the scale has sufficient internal consistency for research. Therefore, it seems that our Reflective Ability Scale can be a reliable measure of reflective ability of clinical nurses. In summary, this study demonstrated the construct validity, criterion-related validity, and reliability of our Reflective Ability Scale, suggesting that the scale may effectively assess the reflective ability of clinical nurses.

This study investigated the reliability and validity of the Reflective Ability Scale we developed using cross-sectional data. This study had some limitations. First, there might be bias in the selection of study participants because all of the study sites were located in one prefecture, and the nursing department director selected the participants at some sites. Second, there might have been bias in responses depending on the circumstances at the time the questionnaire was completed. Going forward, we hope to increase the reliability and validity of the Reflective Ability Scale in this study by conducting studies to investigate its stability using the retest method, to investigate cross-reliability by increasing the number of hospitals included, and to investigate the criteria-related validity using multiple external criteria, which will in turn refine the scale.

Reflection is a process of intentional thinking, and it is necessary to examine the unique experiences that nurses gain during nursing practice and the characteristics of their emotions and ways of thinking that have become unconscious parts of routine practice. In this study, the development of a scale for evaluating reflective ability resulted in a meaningful tool that allowed us to understand the current state of an individual's reflective ability and the details thereof that should be improved. Future studies to investigate validity, which will ask questions such as how to capture changes in reflective ability due to continuous reflection longitudinally, will be required.

Acknowledgments: We would like to thank the following medical institutions for their cooperation in this study: Tottori University Hospital, Tottori Municipal Hospital, Tottori Prefectural Central Hospital, Japanese Red Cross Tottori Hospital, Tottori Prefectural Kousei Hospital, Tottori Medical Center, and Sanin Rosai Hospital.

This paper is a corrected and updated version of the one 
presented at the 40th Annual Conference of Japan Academy of Nursing Science.

\section{The authors declare no conflicts of interest.}

\section{REFERENCES}

1 Tamura Y, Tsuda N. [Reflection: concept and significance in nursing education and nursing research]. The Japanese journal of nursing research. 2008;41:171-81. Japanese.

2 Teekman B. Exploring reflective thinking in nursing practice. J Adv Nurs. 2000;31:1125-35. DOI: 10.1046/j.13652648.2000.01424.x, PMID: 10840246

3 Dewey J. DEMOCRACY and EDUCATION An introduction to the philosophy of education. New York: The Macmillan Company; 1961. p. 145.

4 Schön D. The Reflective Practitioner: How Professionals Think in Action. New York: Basic Books; 1983. p. 62-69.

5 Nishida E. [Perspectives for basic theory of "Caring" in nursing: What is the "Caring"]. Journal of Japanese Nursing Ethics. 2018;10:8-15. DOI: 10.32275/jjne.10.1_8 Japanese with English abstract.

6 Tamura Y, Ikenishi E. [Activating reflection in nursing education and practice: a key to flourishing in nursing]. Tokyo: NANKODO; 2014. Japanese.

7 Higashi M. [Introduction to nursing reflection: learn from experience and create new nursing]. Yokohama: Life Support Company; 2009. Japanese.

8 Ueda N, Miyazaki M. [Review of literature on reflection by nursing practitioner]. Journal of Chiba Academy of Nursing Science. 2010;16:61-8. https://opac.ll.chiba-u.jp/da/curator/900071851/13448846_16-1_61.pdf Japanese.

9 Burns S. [Reflective practice in nursing: the growth of the professional practitioner]. Bulman C, editor. Tamura Y, NakadaY, Tsuda N, supervisor of translation. Tokyo: Yumiru Publishing; 2005. Japanese.

10 Wiedenbach E. [Clinical nursing: a helping art. Revised 2nd ed]. Toguchi T, Ikeda A, translator. Tokyo: GENDAISHA; 1969. p. 27-29, 69. Japanese.

11 Ueta I, Kawanishi C, Tanioka T. [Development of the Reflection and Self-Assessment scale for nursing students: study of its reliability and validity]. The Journal of Nursing Investigation. 2012 March 30;10(1-2):1-8. Japanese. Available from: https://www.tokushima-u.ac.jp/fs/1/9/0/5/2/8//Vol_10-1.pdf

12 Maruyama I, Matsunari Y, Nakayama Y, Kudo $\bar{M}$, Ishii K, Ishihara $\mathrm{M}$, et al. [Goodness of fit index of clinical nursing competence self-assessment scale]. Bulletin of Fukushima Medical University School of Nursing. 2011;13:11-8. Available from: https://ir.fmu.ac.jp/dspace/bitstream/123456789/245/1/ BullFukushimaSchNurs_13_p11.pdf Japanese.
13 Takase M, Teraoka S. Development of the Holistic Nursing Competence Scale. Nurs Health Sci. 2011;13:396-403. DOI: 10.1111/j.1442-2018.2011.00631.x, PMID: 21883769

14 Kimura M, Tateno Y, Sekine M, Nakahara J. [Development of the Experiential Learning Inventory on the Job]. Research report of JET Conferences. 2011;4:147-52. Japanese.

15 Sadahiro W, Yamashita N. [Development of the SelfEvaluation Scale of Oriented Problem Solving Behavior in Nursing Practice (OPSN)]. The Japanese journal of nursing research. 2002;35:483-94. Japanese.

16 Ueda T, Kameoka T, Funashima N, Nomoto Y. [Expertise in Nursing Practice of Hospital Based Nurses]. Japan Academic Society of Nursing Education. 2005;14:37-50. DOI: 10.19015/ jasne.14.1_37. Japanese with English abstract.

17 Sasaki M, Hariu T. Development of the Professional Identity Scale for Nurses (PISN). Journal of Japan Academy of Nursing Science. 2006;26:34-41. DOI: 10.5630/jans.26.1_34 Japanese with English abstract.

18 Kawamoto R, Hatono Y, Cho S, Maeno Y. [The Basics and Tips of Nursing Research Using "Scale" - For Improving the Accuracy and Shortening the Time of Nursing Research]. Japanese Nursing Association Publishing Company; 2016. Japanese.

19 Inagaki S, Osawa A, Yoshikawa A, Ishihara I. [Development and validation of the Japanese version of the Hospital Ethical Climate Survey]. Journal of Japanese Nursing Ethics. 2020;12:73-9. DOI: 10.32275/jjne.12.1_73 Japanese.

20 Nanya S, Fujiwara N, Yanagisawa S, Fukada J. Development of Collaboration Consciousness Scale for Full-Time Nurses in Working with Part-Time Nurses in General Wards. Journal of Japan Academy of Nursing Science. 2016;36:189-97. DOI: 10.5630/jans.36.189 Japanese with English abstract.

21 Toyoda H. [Analysis of Covariance Structure (Amos) Structural Equation Modeling]. Tokyo: Tokyo Tosho Co., Ltd; 2007. Japanese.

22 Dewey J. How We Think. Boston: D. C. Heath and Company; 1910.

23 Korthagen FJ. Linking Practice and Theory: The Pedagogy of Realistic Teacher Education. London: Routledge; 2001. p. 4244, 203-214.

24 Sakata T, Nakada M, Murai N, Yano H, Yamabe E. The Book of Reflection. Tokyo: GAKUBUNSHA; 2019. Japanese. 